\title{
EISCAT/CRRES observations: nightside ionospheric ion outflow and oxygen-rich substorm injections
}

\author{
N. G. J. Gazey ${ }^{1}$, M. Lockwood ${ }^{1}$, M. Grande ${ }^{1,6}$, C. H. Perry ${ }^{1}$, P. N. Smith ${ }^{2}$, S. Coles ${ }^{2}$, A. D. Aylward ${ }^{1,3}$, \\ R. J. Bunting ${ }^{4}$, H. Opgenoorth ${ }^{5}$, B. Wilken ${ }^{7}$ \\ 1 Rutherford Appleton Laboratory, Chilton, Oxfordshire, OX11 0QX, UK \\ Space Science Centre, Sussex University, Falmer, BN1 9QH, UK \\ 3 Atmospheric Physics Laboratory, UCL, London, W1P 7PP, UK \\ ${ }^{4}$ Department of Physics, York University, York, YO1 5DD, UK \\ 5 Institutet för Rymdfysik, Uppsala, 75591 Uppsala, Sweden \\ ${ }^{6}$ Space Physics Department, Warwick University, Coventry, CV4 7AL, UK \\ 7 Max-Planck Institut für Aeronomie, Katlenburg-Lindau, 37189, Germany
}

Received: 10 April 1995/Revised: 19 April 1996/Accepted: 25 April 1996

\begin{abstract}
We present combined observations made near midnight by the EISCAT radar, all-sky cameras and the combined released and radiation efects satellite (CRRES) shortly before and during a substorm. In particular, we study a discrete, equatorward-drifting auroral arc, seen several degrees poleward of the onset region. The arc passes through the field-aligned beam of the EISCAT radar and is seen to be associated with a considerable upflow of ionospheric plasma. During the substorm, the CRRES satellite observed two major injections, $17 \mathrm{~min}$ apart, the second of which was dominated by $\mathrm{O}^{+}$ions. We show that the observed arc was in a suitable location in both latitude and MLT to have fed $\mathrm{O}^{+}$ions into the second injection and that the upward flux of ions associated with it was sufficient to explain the observed injection. We interpret these data as showing that arcs in the nightside plasma-sheet boundary layer could be the source of $\mathrm{O}^{+}$ions energised by a dipolarisation of the mid- and near-Earth tail, as opposed to ions ejected from the dayside ionosphere in the cleft ion fountain.
\end{abstract}

\section{Introduction}

A number of authors (e.g. Baker et al., 1982) have discussed the possible role of ionospheric $\mathrm{O}^{+}$ions in triggering substorm onset. The presence of increasing amounts of $\mathrm{O}^{+}$in the magnetospheric plasma can increase the growth rate of the ion-tearing mode instability, and this instability has been invoked to explain the sudden disruption of the cross-tail current prior to substorm onset (Büchner and Zelenyi, 1987). The concentration of $\mathrm{O}^{+}$in the magnetosphere has also been observed to increase during the early growth phase of substorms. Daglis et al. (1991), using AMPTE-CCE ion data, showed that the partial pressure

Correspondence to: N. Gazey of all the major ion species, $\mathrm{H}^{+}, \mathrm{O}^{+}$and $\mathrm{He}^{2+}$, increases during the stretching of the tail field, but that while $\mathrm{H}^{+}$ remains the dominant ion of the three, the largest relative increase in pressure is seen in $\mathrm{O}^{+}$. A further study by Daglis et al. (1994) showed the excellent correlation between $\mathrm{O}^{+}$energy density and $\mathrm{AE}$, and in particular between $\mathrm{O}^{+}$energy density and $\mathrm{AU}$, which increases in the growth phase, prior to onset. Given the almost complete absence of $\mathrm{O}^{+}$from the solar wind (Bame et al., 1970; Prange, 1978; Johnson, 1979), the ionosphere must be active in feeding the magnetosphere during the growth phase. Since auroral electron precipitation and in particular auroral arcs are associated with upward beams of $\mathrm{O}^{+}$ ions (Shelley et al., 1982), auroral arcs provide one means of populating the near-Earth plasma sheet with $\mathrm{O}^{+}$.

Ionospheric $\mathrm{O}^{+}$ions flow into the magnetosphere as beams (the result of field-parallel acceleration) or conics (due to transverse acceleration). Beams are associated mainly with outward field-aligned currents. Some beams are composed entirely of $\mathrm{O}^{+}$and some entirely of $\mathrm{H}^{+}$ (Kintner et al., 1979). According to Frank et al. (1977), a flux of $10^{12} \mathrm{~m}^{-2} \mathrm{~s}^{-1}$ of $\mathrm{O}^{+}$must leave the topside auroral ionosphere to explain fluxes of $\mathrm{O}^{+}$observed at $35 R_{E}$, an estimate which is consistent with observations of outflow (with energies $E>5 \mathrm{eV}$ ) made by the ISIS-2 spacecraft below $1 R_{E}$ (Klumpar, 1979). Auroral oxygenion outflow is most profuse at low energies $(0-100 \mathrm{eV})$, as demonstrated by observations of thermal $\mathrm{O}^{+}$upflows deduced from topside profiles by Lockwood (1982) and observations of thermal magnetospheric plasma by the RIMS experiment on DE-1 (Chappell, 1982; Moore et al., 1984; Chandler, 1991). Above $550 \mathrm{eV}$, the flux of $\mathrm{O}^{+}$in auroral ion beams can exceed that of $\mathrm{H}^{+}$by a factor of 5 (Ghielmetti et al., 1979; Gorney et al., 1981; Collin et al., 1981).

Upward flows of ionospheric ions have been confirmed by EISCAT radar studies (Jones et al., 1988; Winser et al., 1989; Keating et al., 1990; Wahlund et al., 1992). Keating et al. (1990) performed a statistical survey of high-flux field-aligned flows seen by EISCAT and showed that they 
were most likely to occur in the winter between $19^{00}$ and $04^{00} \mathrm{UT}$, with their occurrence peaking at about $21^{00} \mathrm{UT}$. At least two distinct types of ion outflow have been found. One is associated with frictional heating events caused by enhanced DC electric fields (Winser et al., 1989) and is characterised by an increase in field-aligned ion velocity and ion temperature but no significant increase in electron density at E-region altitudes. The large ion temperatures and temperature anisotropy $\left(\mathrm{T}_{\perp}>\mathrm{T}_{\|}\right)$in these events indicate the existence of high electric fields. Another class of event (Wahlund et al., 1992) is associated with electron precipitation (indicated by $E$-region density increases) and large electron-temperature increases without a large increase in ion temperature.

The ionosphere provides several other, seemingly continuous, sources of ions to the magnetosphere, namely the polar wind and the cleft ion fountain. The polar wind (Banks and Holzer, 1969) consists of $\mathrm{H}^{+}$and $\mathrm{He}^{+}$ions, expelled from the ionosphere by the ambipolar field generated by the charge separation of the $\mathrm{O}^{+}$gas and the lighter electron gas. The classical theory of the polar wind predicted that the heavier $\mathrm{O}^{+}$ions would be gravitationally bound, but data from the DE-1 satellite showed that high-altitude ion flows sometimes consist almost entirely of $\mathrm{O}^{+}$at low energies. Yau et al. (1984) found that the occurrence probability of $\mathrm{O}^{+}$above $10 \mathrm{eV}$ could be as large as $30 \%$ in the polar cap. Likewise, the RIMS instrument on DE-1 showed that $\mathrm{O}^{+}$ions could be dominant in the polar cap in the energy range $0-50 \mathrm{eV}$ (Waite et al., 1985). Waite et al. found further that in several of the cases that they studied, the $\mathrm{O}^{+}$ions originated from a restricted part of the polar cap and had subsequently been carried towards the nightside by anti-sunward convection. Lockwood et al. (1985a) identified this persistent source of upflowing ionospheric ions (including $\mathrm{O}^{+}$) in the energy range $1-20 \mathrm{eV}$ as coming from the cleft, and subsequently coined the term "cleft ion fountain" (Lockwood et al., 1985b).

Ionospheric ion upflows bear a complex relationship to actual $\mathrm{O}^{+}$outflow into the magnetosphere. Ion upflow in the ionosphere consists mainly of $\mathrm{O}^{+}$ions, but this supports in part the escape of $\mathrm{H}^{+}$via charge exchange. The flux of $\mathrm{H}^{+}$escaping into the magnetosphere has a maximum value and $\mathrm{O}^{+}$escape is often inferred from lowaltitude upflows which exceed this value. It is also unclear how much of the $\mathrm{O}^{+}$upflow simply falls back to the Earth at a later time under gravity (Chandler, 1995). Furthermore, upflows can be part of a thermal expansion of the ionosphere, the ions subsequently returning when it contracts again. However, the elevation of ions to an altitude where transverse or parallel acceleration can act to give them sufficient velocity to overcome gravity will enhance $\mathrm{O}^{+}$escape fluxes. Ions with the greatest parallel velocity are carried farthest down the tail by high-latitude convection. Since the velocity of $\mathrm{O}^{+}$ions is four times less than that of protons of the same energy, the time of flight of $\mathrm{O}^{+}$ ions along a given field-aligned path is four times larger than that of $\mathrm{H}^{+}$, and the distance moved by the convecting field line is likewise that much larger. This means that convection influences $\mathrm{O}^{+}$trajectories far more than $\mathrm{H}^{+}$ trajectories, and that $\mathrm{O}^{+}$from the nightside auroral oval

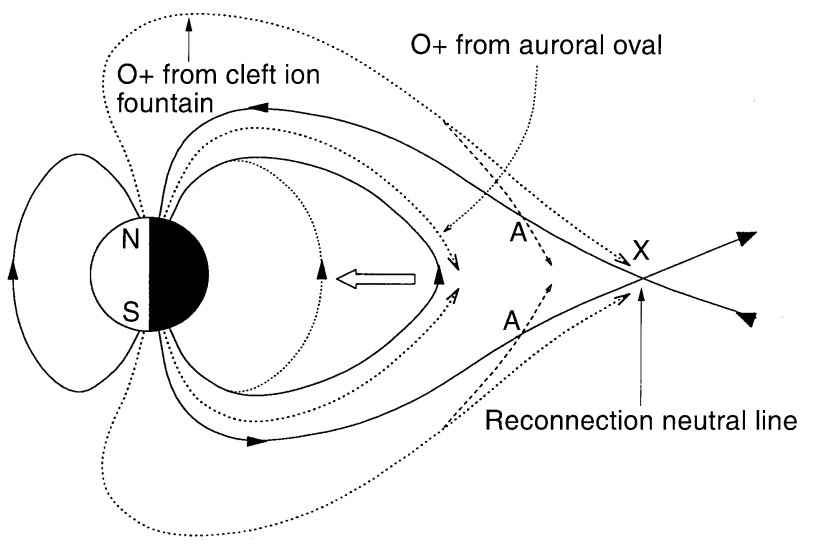

Fig. 1. A schematic illustration of the respective paths into the magnetosphere of $\mathrm{O}^{+}$ions from the dayside cleft and the nightside auroral ionosphere. The empty arrow represents the dipolarisation convection surge. X marks the tail reconnection neutral line. Reconnection at $\mathrm{X}$ allows cleft-ion-fountain plasma to cross the open/closed field line boundary closer to the Earth (at A)

will tend to be deposited in the near-Earth tail $\left(\mathrm{GSM} / \mathrm{GSE} \mathrm{X}=-5\right.$ to $\left.-10 R_{E}\right)$.

It has been suggested that ions from the cleft may contribute to substorm onset (Cladis and Francis, 1992). To be seen in the energetic particle injection associated with the substorm expansion phase, the $\mathrm{O}^{+}$must already be present in the magnetosphere on the field lines which dipolarise in the convection surge. Ions that come from the cleft are initially on open field lines and stay frozen on to the field lines along which they were ejected as the field lines convect across the polar cap. Therefore, for cleft-ionfountain ions to gain access to the onset region, they must first cross the open/closed field-line separatrix (A in Fig. 1) which can only happen if there is ongoing closure of open flux at the neutral line during the growth phase. The only alternative to this is through violation of the frozen-in approximation, such as finite gyro-radius effects. However, it is unlikely that these can on their own give rise to large-scale transport of ions across the separatrix. Without growth phase reconnection at the neutral line, cleftion-fountain ions travel down the tail lobe and have no access to the onset region (an alternative trajectory, which is also shown in Fig. 1). Since the travel time from the cleft to the onset region is typically several hours (as demonstrated by the convection time in the ionosphere; see also simulations by Cladis and Francis, 1992), there is insufficient time for $\mathrm{O}^{+}$leaving the cleft in the growth phase to reach the onset region by the time of onset at the end of that growth phase. This is true even if tail reconnection does take place during the growth phase. It is now believed that substorm onset occurs on closed field lines at the inner edge of the plasma sheet (Elphinstone et al., 1991; Samson et al., 1992a, b, Murphree et al., 1993; Lopez et al., 1993; Gazey et al., 1995); the evidence for this has recently been reviewed by Lockwood (1995). Ions which have been ejected into the magnetosphere from the closed field-line region, e.g. by an arc equatorward of the open/closed field-line boundary, but poleward of the onset region, already find themselves on closed field lines and 
therefore have direct access to the onset region without the need for any pre-onset reconnection to take place. The two possible sources of $\mathrm{O}^{+}$are illustrated in Fig. 1 .

\section{Observations}

The interval under discussion in this paper is $21^{20}-22^{30}$ UT on 7 March 1991. From the magnetogram recorded at Tromsø (Fig. 2), we see that this interval encompassed the third in a sequence of substorms that occurred on that evening and, as for the previous two, the electrojet signature indicates a westward electrojet, centred to the south of Tromsø. Data on the interplanetary magnetic field (IMF) from the IMP-8 satellite (Fig. 3) show that the $Z$ component had been negative (at the spacecraft) since about $20^{20} \mathrm{UT}$, and thus that open magnetospheric flux is likely to have been generated for at least an hour and a half before this substorm occurred.

We also call upon data from the combined release and radiation effects satellite (CRRES) (Wilken et al., 1992), which flew in a geosynchronous transfer orbit, inclined at $18^{0}$ to the equatorial plane, with apogee at $6.3 R_{E}$. The spin period was about $27 \mathrm{~s}$. From December 1990 until April 1991, a period which encompassed the observations presented here, apogee was within a few hours of local midnight. With CRRES' orbit being nearly geostationary near apogee, it was well placed to measure nightside substorm phenomena. Figure 4a pictures orbit 548 of the satellite, with the interval covered by Fig. $4 \mathrm{~b}\left(21^{20}-23^{20}\right.$ UT, 7 March 1991) marked in bold. The nightside of the Earth is coloured black and the axes are measured in units of Earth radii in the GSM coordinate system. In the upper panel, the orbit is shown from the viewpoint of the dawn sector of the equatorial plane, while in the lower panel one looks down upon the equatorial plane from above the north pole. During the period $21^{20}-22^{30}$ UT, CRRES was quite near to the magnetic equatorial plane and also west of EISCAT, although it was on an $L$-shell $(L=6.6)$ close to EISCAT's. Figure 4b traces CRRES' northern magnetic footprint. CRRES was within the domain of the Earth's internal magnetic field during the period of interest.

Figure 5 shows data from the magnetospheric ion composition spectrometer (MICS) instrument which measured atomic mass and charge states of ions in the range $1-425 \mathrm{keV} / Q$ (Wilken et al., 1992). Ions entering the instrument passed through three detector stages: the electrostatic analyser, in which only ions of particular energy-tocharge ratio $(E / Q)$ could traverse the full length of the analyser (voltage varied in 32 logarithmic steps from 1-425 keV); the time-of-flight detector which allowed the energy-to-mass ratio $(E / m)$ to be measured; and a solidstate detector which measured the total energy $(E)$ of ions above $40 \mathrm{keV}$ which had made it there. This triplet of measurements yields $E, m$ and $Q$. The colour contours of Fig. 5 show spin-averaged count rates, which are nearly proportional to differential number flux $\left(\mathrm{m}^{-2} \mathrm{~s}^{-1} \mathrm{sr}^{-1}\right)$. The top panel (DCR) shows all counts which registered a time of flight in the MICS instrument. The next two panels show counts of alpha particles $\left(\mathrm{He}^{2+}\right)$ and oxygen ions $\left(\mathrm{O}^{+}\right)$, respectively. Note that most of the counts which figure in the DCR panel are due to hydrogen ions $\left(\mathrm{H}^{+}\right)$, not $\mathrm{He}^{2+}$ or $\mathrm{O}^{+}$.

The dispersive features visible on the plots are termed drift echoes and arise because ions from a given injection drift round the Earth at different speeds due to grad-B drift, according to their energy per unit charge $(E / Q)$. Superimposed upon Fig. 5 are simulated drift echoes for ions in a dipole magnetic field (Grande et al., 1992). The drift motion of particles in the energy range of the MICS instrument arises predominantly from magnetic-field gradient effects, the effect of electric fields being negligible. In the modelling, ions are assumed to be trapped at the

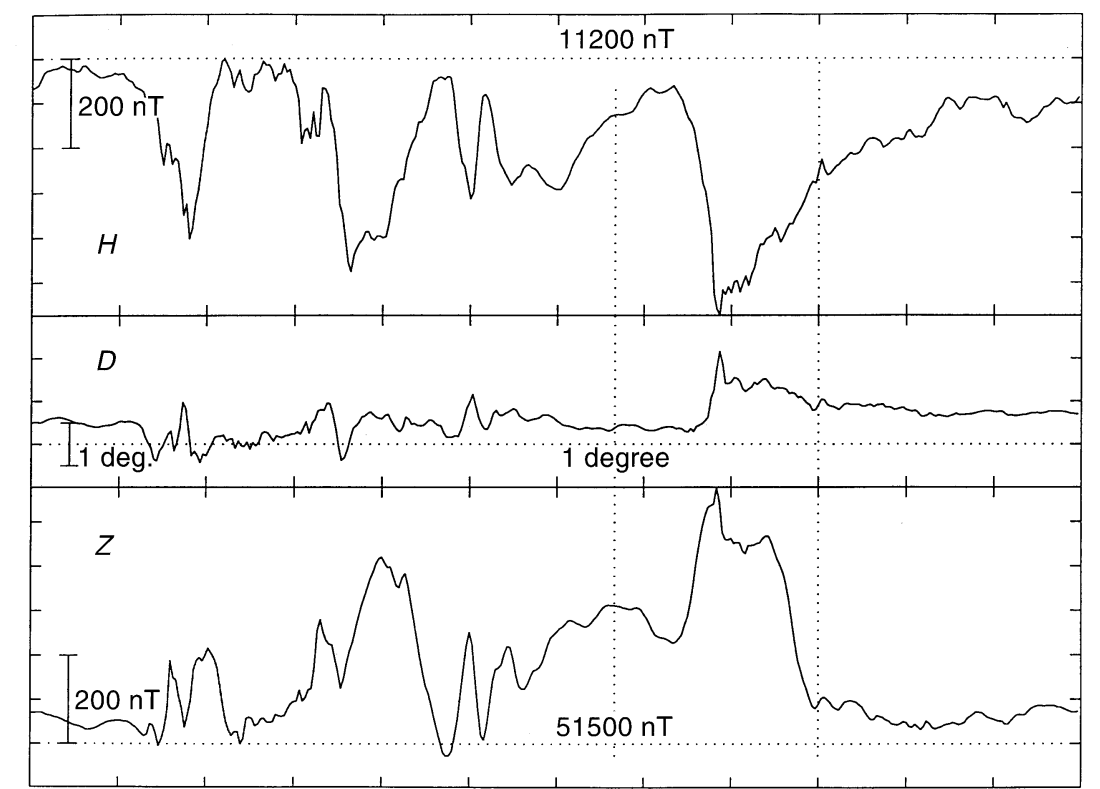

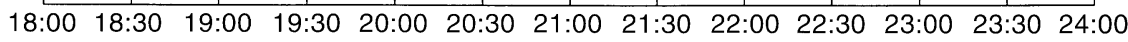

Fig. 2. The magnetogram recorded at Tromsø Auroral Observatory on 7 March 1991. Negative $H$ indicates a westward electrojet. Positive $Z$ indicates that the electrojet is to the south of Tromsø. The dotted lines span the interval $\left(21^{20}-22^{30} \mathrm{UT}\right)$ covered by the EISCAT and magnetometer data given in Figs. 7,8 and 6 , respectively 


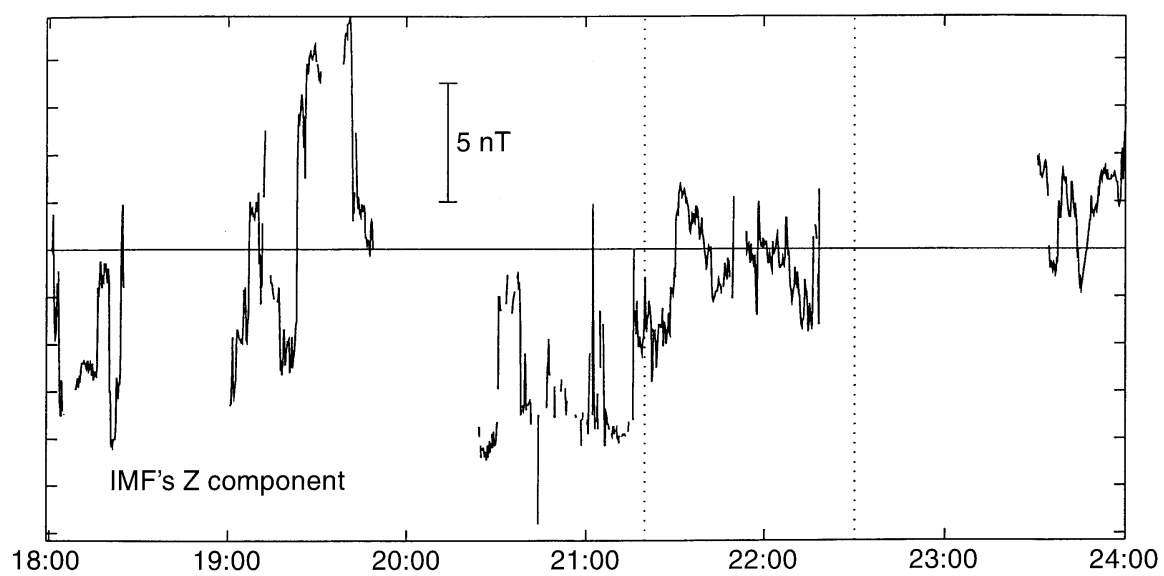

Fig. 3. The IMF's $Z$ component measured in the solar wind by the IMP-8 satellite (position $\{29.7,12.3,-15.1\} R_{E}$ in GSM). The dotted lines span the interval $\left(21^{20}-22^{30}\right.$ UT) covered by Figs. $6-8$
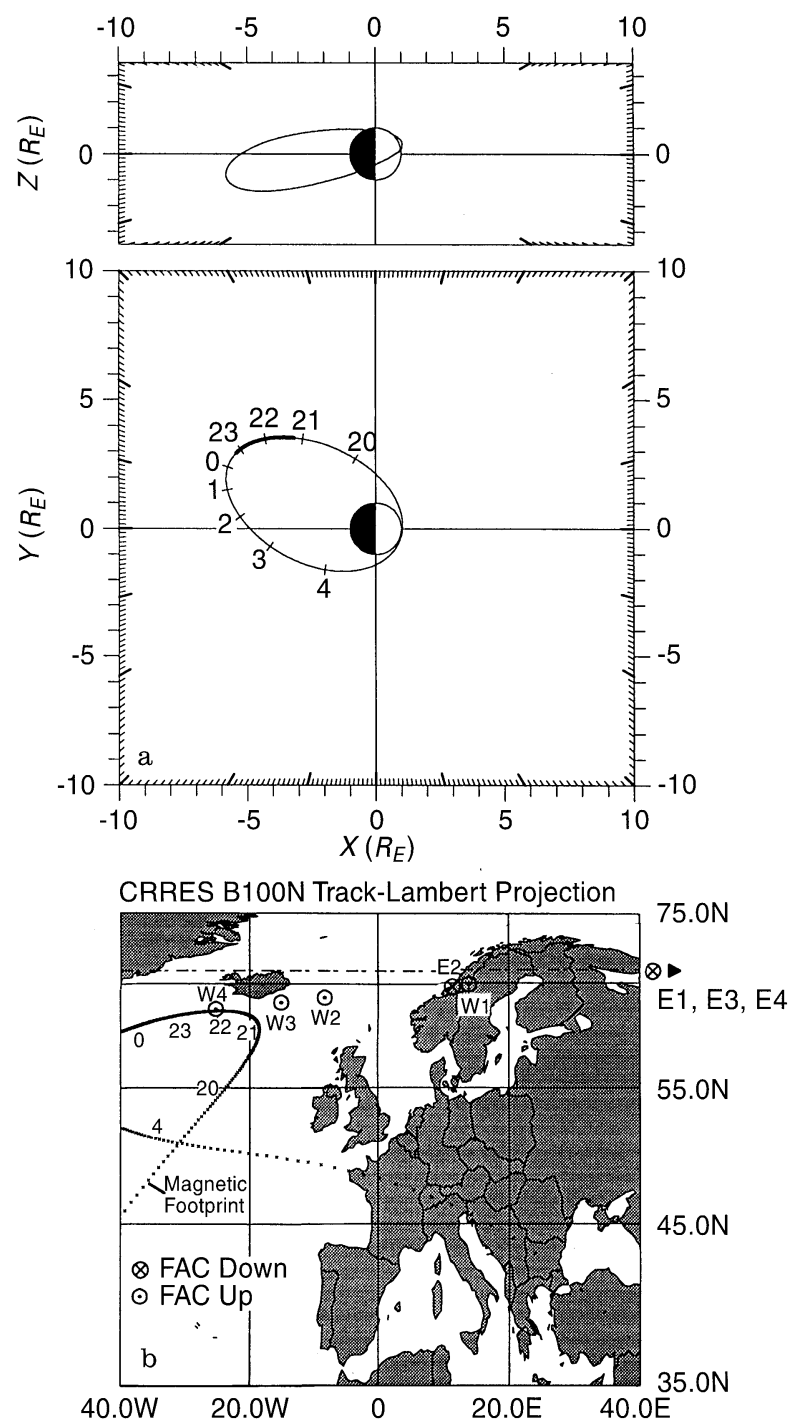

Fig. 4a, b. Orbital parameters for CRRES' orbit 548; a in GSM coordinates. The solid line marks the orbit segment for the time spanned by Fig. 5; b CRRES' northern magnetic footprint for orbit 548. Also plotted are the positions of the substorm electrojet as it progressed westwards. W1 and E1 are the westward and eastward ends of the current wedge for $21^{39} \mathrm{UT}$; W2 and E2 are for $21^{44} \mathrm{UT}$; $\mathrm{W} 3$ and $\mathrm{E} 3$ are for $21^{52} \mathrm{UT}$; and W4 and E4 are for $21^{56} \mathrm{UT}$ magnetic equator and to drift westwards in circular orbits with a period proportional to the reciprocal of ion $E / Q$ and geocentric distance (Lyons and Williams, 1984). The UT and MLT of each simulated drift echo is varied to match the observations and the best-fit injection location in UT, and MLT is given in the bottom left-hand corner of Fig. 5. The model reproduces the observed drift echoes fairly accurately, despite its simplicity. This means that we can estimate the injection location of $\mathrm{O}^{+}$and $\mathrm{He}^{2+}$ ions observed by MICS, which is crucial in trying to compare CRRES and EISCAT observations when CRRES was magnetically west of EISCAT. Figure 5 shows two simulated drift echoes, one from the first major injection seen by CRRES (black line) which contained both $\mathrm{He}^{2+}$ and $\mathrm{O}^{+}$ions and the second (grey line) from a subsequent oxygen-rich injection. Modelling of the first, $\mathrm{He}^{2+}$-rich, injection places it at $21^{43}$ UT $\left(22^{34}\right.$ MLT) while the subsequent $\mathrm{O}^{+}$-rich injection seems to have taken place at $22^{00}$ UT $\left(22^{58} \mathrm{MLT}\right)$. The location of the injection point in UT is fairly well determined by the modelling, although the deduced injection MLT may be out by up to about 30 min. Nevertheless, the modelling does show that the injections occurred at an MLT close to EISCAT's $\left(\sim 23^{30}\right.$ MLT) at that UT.

Substorm onset occurred at $21^{39} \mathrm{UT}$, as deduced from SAMNET magnetometer data (Fig. 6a) (Yeoman et al., 1990). Onset is in evidence both as perturbations in the $H$ components from the various stations (Fig. 6b) and as $\mathrm{Pi} 2$ pulsations in $H$ (Fig. 6c). At all SAMNET sites, with the sole exception of NOR, the deviation in $Z$ (Fig. 6d) at onset was negative, suggesting that the onset electrojet was north of the SAMNET network. Since the Tromsø magnetogram (Fig. 2) indicates that the onset electrojet was to the south of Tromsø, we can surmise that the onset electrojet fell between Tromsø and SAMNET in geomagnmetic latitude. We have applied the York electrojet model (Orr and Craymonson, 1994) to these data. The movement of the substorm electrojet as deduced by this model is represented (approximately, in geographic coordinates) in Fig. $4 \mathrm{~b}$ by a series of dots and crosses representing the field-aligned currents at the ends of the electrojet at various times. In geographic coordinates, the model puts the western end of the onset electrojet at about 

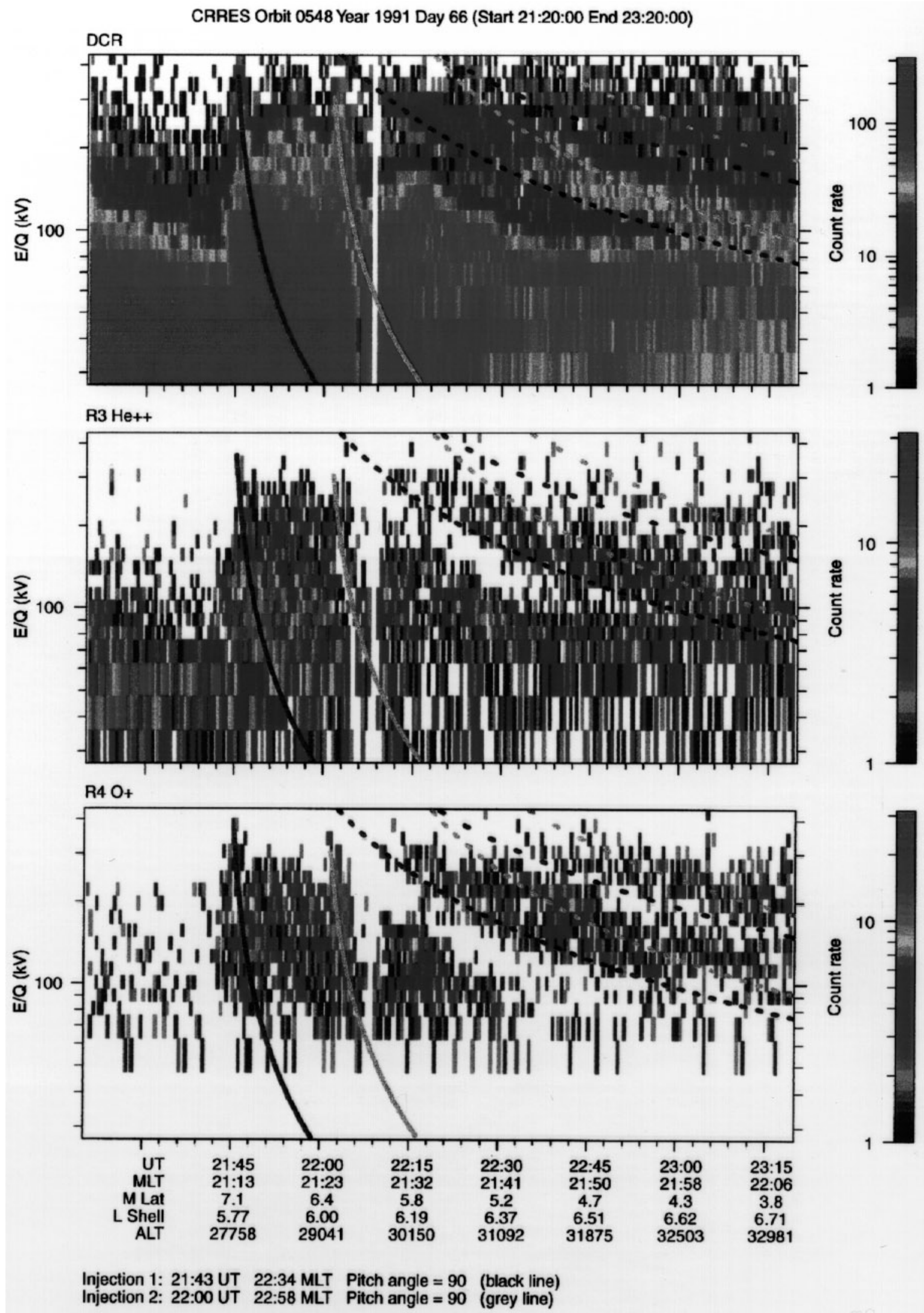

Fig. 5. Particle data from the MICS instrument aboard CRRES for 7 March 1991 (orbit 548). The black lines superimposed upon the data are simulated injection signatures for the $\mathrm{He}^{2+}$-rich injection of
$21^{43}$ UT. The grey lines are simulated injection signatures for the $\mathrm{O}^{+}$-rich injection at $22^{00}$ UT which followed it. Note the instrumental cutoff at low energy in the third panel $\left(\mathrm{O}^{+}\right)$ 


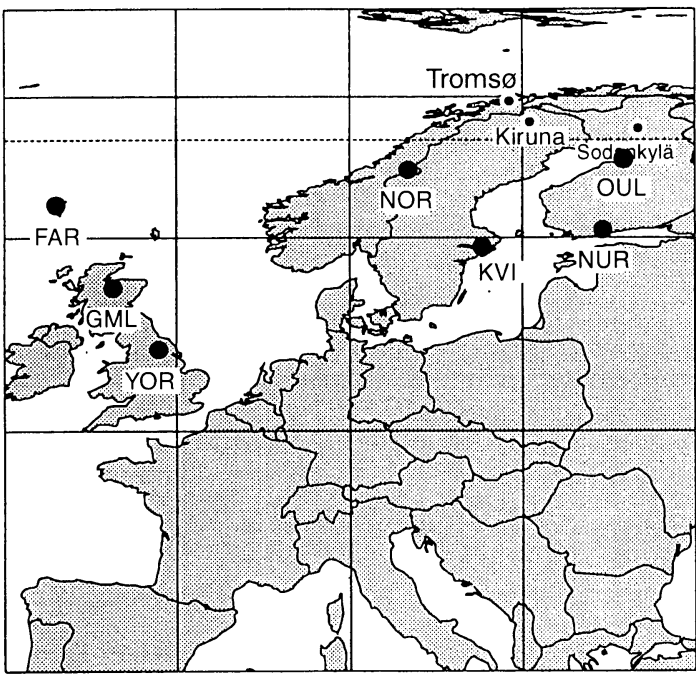

a

Day 66, 1991 : H Component : Filter $(200,40)$

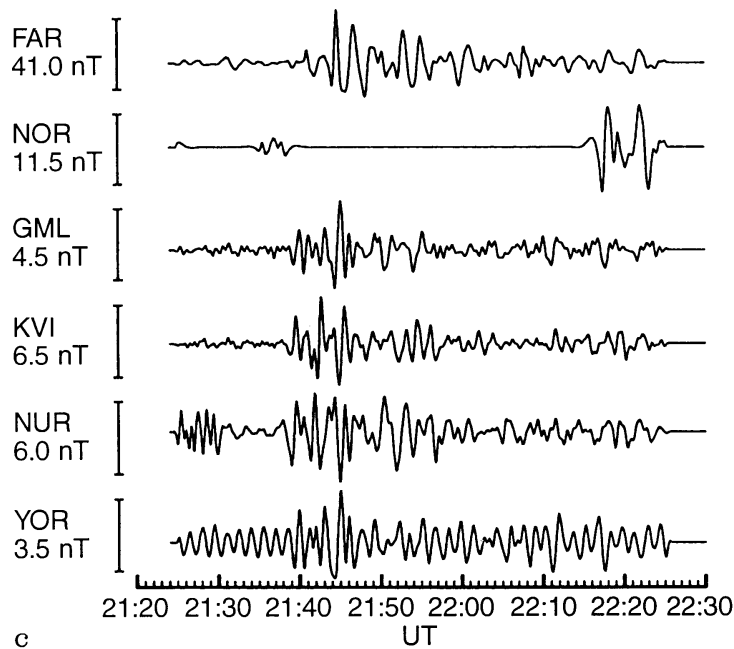

Fig. 6. a The SAMNET magnetometer sites (solid dots) and the EISCAT sites (black dots on white); b Magnetic $H$ components observed by SAMNET stations on 7 March 1991. Note that the Nordli (NOR) magnetometer was saturated between about $21^{20}$ and

$65^{\circ} \mathrm{N}, 10-13^{\circ} \mathrm{E}$ and the eastern end at $67^{\circ} \mathrm{N}, 65^{\circ} \mathrm{E}$, its eastern end therefore stretching well beyond the SAMNET chain (Fig. 4b, [W1, E1]). At about $21^{44}$ UT, a second electrojet appeared, west of the first and on a similar $L$-shell, with its western end at $352^{\circ} \mathrm{E}$ and its eastern end at $12^{\circ} \mathrm{E}$, near the centre of the SAMNET array (Fig. $4 \mathrm{~b}$, [W2, E2]). By $21^{52}$ UT the two electrojets appear to have coalesced into one whose western end had moved westwards to about $345^{\circ} \mathrm{E}$ (Fig. 4b, [W3, E3]). By $21^{56}$ UT the single electrojet had moved still further west to $332^{\circ} \mathrm{E}$ (Fig. 4b, [W4, E4]). By $22^{00}$ UT the current magnitude in the eastern end of the electrojet was falling and had begun to sink everywhere at about $22^{04} \mathrm{UT}$.

Figures 7 and 8 show analysed EISCAT results for the period $21^{20}-22^{30} \mathrm{UT}$. An increase in ionisation typical of an arc can be seen at $21^{27}$ UT (panel 1, Fig. 7), followed by
Day 66, 1991 : H Component : Unfiltered
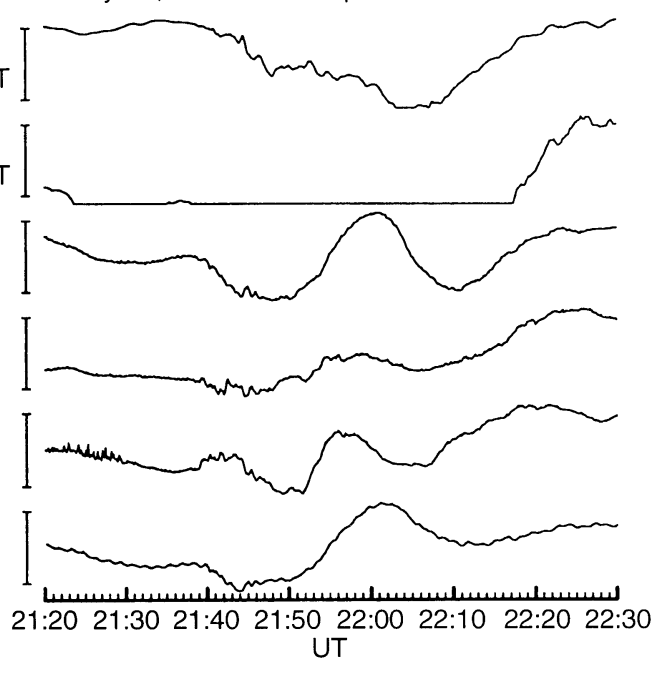

Day 66, $1991:$ Z Component : Unfiltered
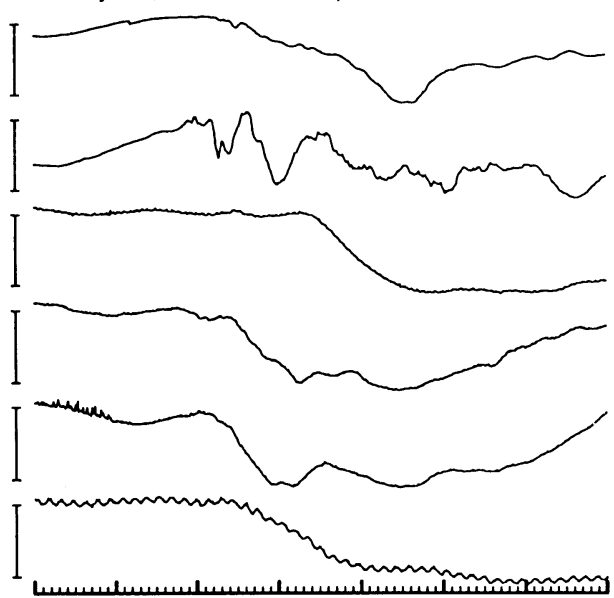

$21: 2021: 3021: 40$ 21:50 22:00 22:10 22:20 22:30

UT

$22^{10} \mathrm{UT}$; c SAMNET $H$ components filtered to show Pi2 pulsations; d Magnetic $Z$ components observed by SAMNET stations on 7 March 1991

a more major increase in ionisation between $21^{49}$ and $21^{59} \mathrm{UT}$, when the substorm expanded polewards over the EISCAT beam. It is clear that the arc at $21^{27}$ UT was associated with a large rise in electron temperature, but not in ion temperature (panels 3 and 4). Also, the fieldaligned velocity (panel 5), both before and after the event was relatively high, and there was a noticeable ion outflux during the event itself (panel 6 , units of $10^{12} \mathrm{~m}^{-2} \mathrm{~s}^{-1}$ ). At $21^{40} \mathrm{UT}$, a series of quasi-periodic electron-density enhancements with a period of $6-8 \mathrm{~min}$ and substructure of period 1-2 min began to populate the region of the EISCAT beam at F-region altitudes. This material probably drifted into EISCAT's field of view from the dayside (Lockwood and Carlson, 1992).

Figure 9 shows an accompanying sequence of all-sky camera pictures taken during the substorm. Tromsø, the 


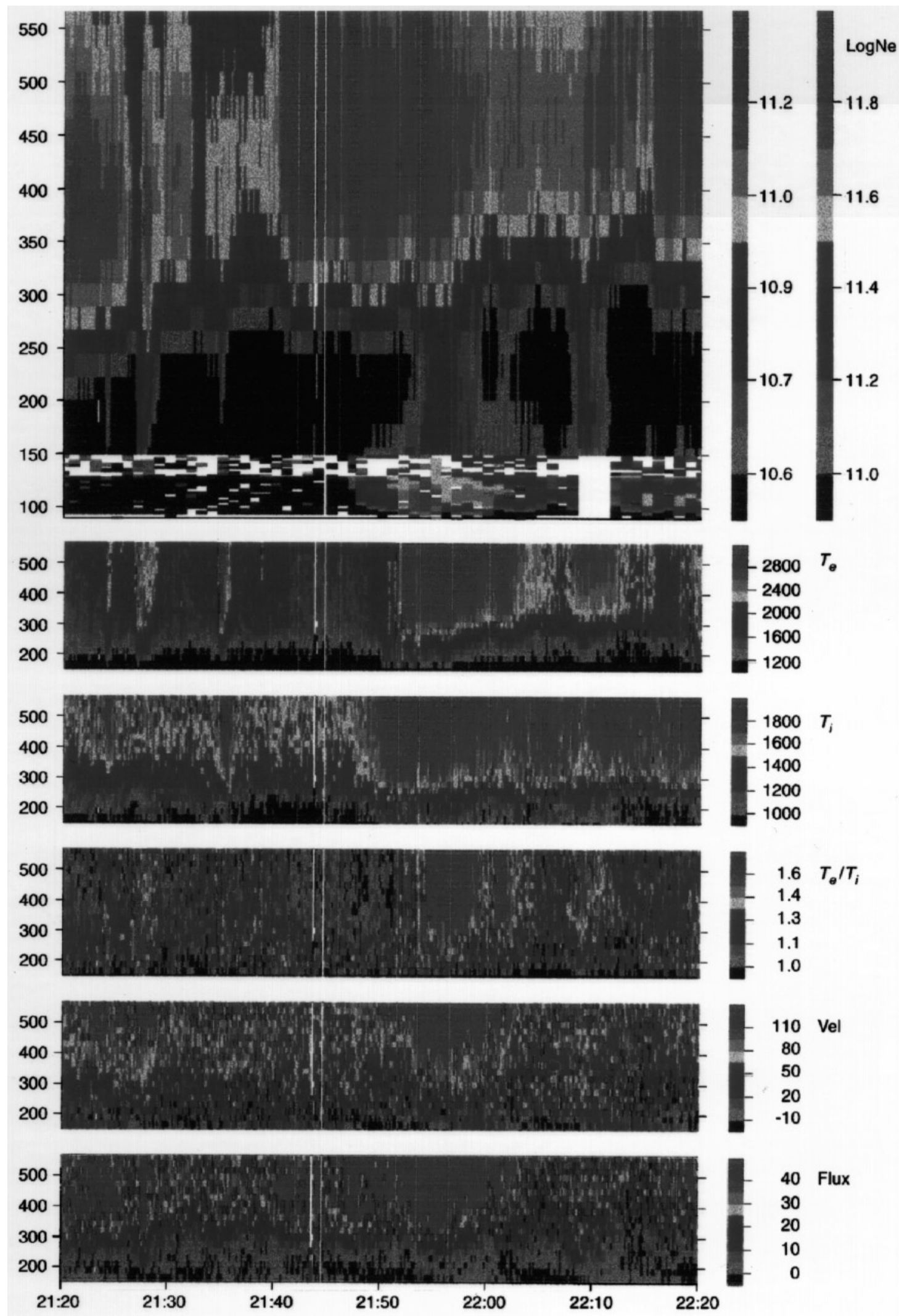

Fig. 7. EISCAT data for the interval $21^{20}-22^{30}$ UT (7 March 1991). All panels show their data colour-coded as a function of altitude and UT for the field-aligned radar beam. The first panel $\left(\log _{10} n_{e}\right.$, measured in $\left.\mathrm{m}^{-3}\right)$ incorporates multipulse data $(90-150 \mathrm{~km})$ at $1-\mathrm{min}$ resolution and long pulse data $(150-570 \mathrm{~km})$ at $10-\mathrm{s}$ resolution. The subsequent panels show electron temperature, $T_{e}(\mathrm{~K})$, ion temper- ature, $T_{i}(\mathrm{~K})$, the temperature ratio $T_{e} / T_{i}$, the field-aligned ion bulk flow velocity $\left(\mathrm{m} \mathrm{s}^{-1}\right)$ and the field-aligned ion flux (in units of $\left.10^{12} \mathrm{~m}^{-2} \mathrm{~s}^{-1}\right)$. The data in the narrow panels comes from the long pulse data alone (150-570 km) while panel 1 includes multipulse data $(90-150 \mathrm{~km})$. The left-hand colour key in panel 1 applies to the multipulse data and the right-hand colour key to the long pulse data 

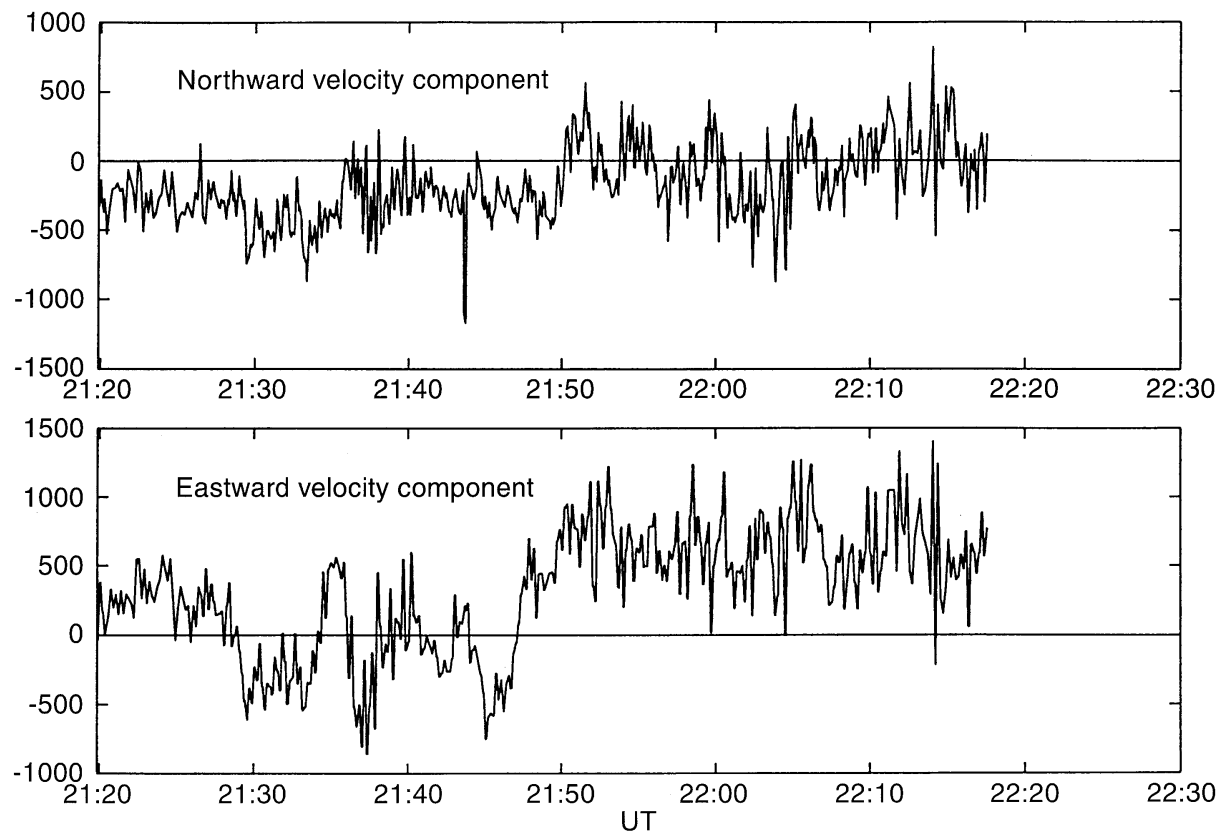

Fig. 8. Field-perpendicular convection velocities seen by EISCAT (as deduced by the tristatic radar technique). No data is available between $22^{17}$ and $22^{30} \mathrm{UT}$ observation site, is at the centre of each plate. At $21^{22} \mathrm{UT}$ a faint, magnetically east-west aligned arc appeared to the north of Tromsø (Fig.9a), developing a kink by $21^{23}{ }^{30} \mathrm{UT}$ (Fig. 9b). As this arc moved southwards (Fig. 9c, d), the kink gradually straightened out and the arc was fading as it passed through the EISCAT beam at approximately $21^{27}$ UT. As it did so, it caused the arc signatures in the EISCAT data - panel 6, Fig. 7, for example, shows the clear upflux of ionospheric plasma associated with it. The arc over Tromsø finally faded by $21^{29}$ UT. At $21^{40}$ UT (Fig. 9e), shortly after onset, the poleward edge of the bulge brightened and moved northwards, eventually engulfing the scattering volume and causing the expansion phase signatures in the EISCAT data (Fig. 7).

\section{Discussion}

We wish to consider whether $\mathrm{O}^{+}$ions ejected in the upflow that was associated with the southward-drifting pre-onset arc could have appeared in the $\mathrm{O}^{+}$injections measured by CRRES, or whether these energetic ions came from the cleft ion fountain on the dayside. Southward convection (Fig. 8) would then have carried the flux tube equatorwards until it arrived at the ionospheric onset location. Consider a nightside flux tube which crosses the Earth's equatorial plane at about $10 R_{E}$, which we take to be the approximate onset location. Ions ejected from the topside ionosphere must travel approximately $15 R_{E}$ along the flux tube before reaching the central plasma sheet. To make an order-of-magnitude estimate of the flight time of $\mathrm{O}^{+}$ions along the flux tube, let us consider the ions in question to be weakly accelerated in the topside ionosphere and have an energy of $25 \mathrm{eV}$ until they reach a distance of $1 R_{E}$ along the flux tube, whereupon they are accelerated to about $1 \mathrm{keV}$, becoming an ion beam. Using simple considerations, one arrives at a flight time of approximately $15 \mathrm{~min}$. If we reduce the assumed energy of the $\mathrm{O}^{+}$below $1 R_{E}$ to $5 \mathrm{eV}$, we increase the travel time to approximately $21 \mathrm{~min}$.

For ions ejected via the arc to have entered the onset region and there to be energised (so as to be detected by CRRES), the foot of the flux tube on to which they are frozen must have reached the ionospheric location of onset - namely the bright auroral bulge visible to the very south of the all-sky-camera field of view - by the time onset occurred. Note that a flux tube moves with the plasma velocity, not the arc velocity, and that the arc may, in fact, move through the background plasma (Haerendel et al., 1993; Gazey et al., 1995). The all-sky camera subtends an angle of about $150^{\circ}$. Elevation can be measured off the images linearly over this range. At an emission height of about $120 \mathrm{~km}$, therefore, the field of view has a span of about $900 \mathrm{~km}$. The southward velocity of the background plasma before the arc entered the beam was about $250 \mathrm{~m} \mathrm{~s}^{-1}$ and after it had passed through the beam about $500 \mathrm{~m} \mathrm{~s}^{-1}$ (we cannot tell whether the flow speed differed greatly from these values when the arc was away from the EISCAT beam, but assume that they do not). At the first of these two speeds, the foot of the flux tube would have moved about $350 \mathrm{~km}\left(\sim 3.1^{\circ}\right.$ invariant latitude $)$ and for the second speed about $475 \mathrm{~km}\left(\sim 4.2^{\circ}\right.$ invariant latitude) in the $F$ region between the arc's appearance to the north of Tromsø and the arrival of ejected $\mathrm{O}^{+}$ions in the plasma sheet. Since the distance in the ionosphere between the place where the arc appeared and the location of the onset bulge is $450-500 \mathrm{~km}$, it is in either case feasible (to the accuracy of this calculation), that southward convective flow was fast enough to carry the $\mathrm{O}^{+}$ejected by the arc into the onset region, i.e. the southward-drifting arc described here would have been in a suitable location to act as a source of the $\mathrm{O}^{+}$seen at onset. 


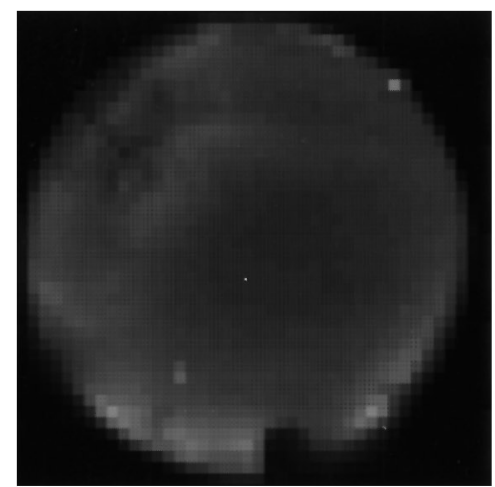

(a) 21:21:59 UT

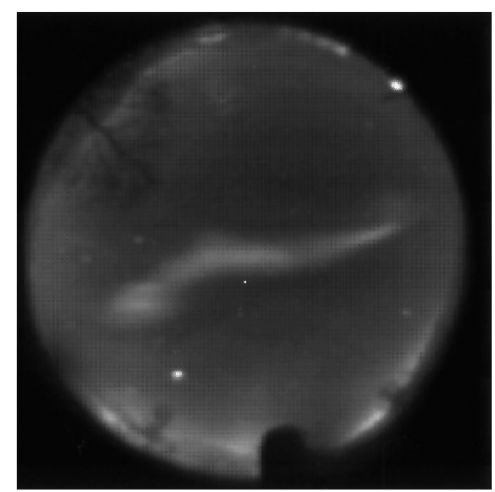

(d) 21:26:32 UT

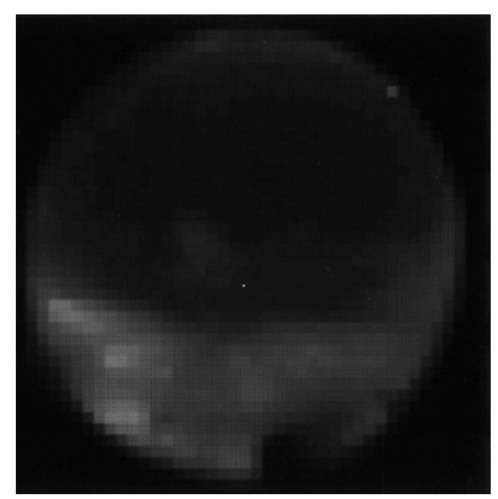

(g) 21:48:28 UT

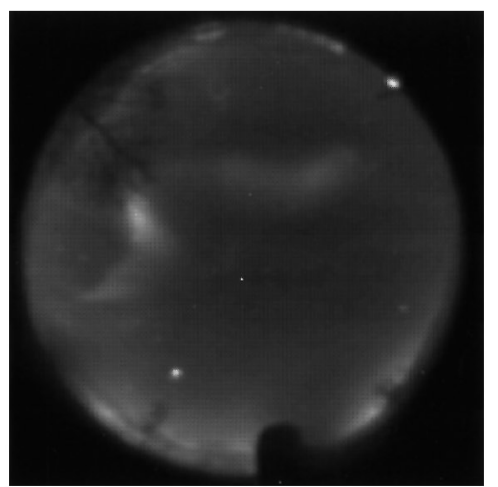

(b) $21: 23: 32$ UT

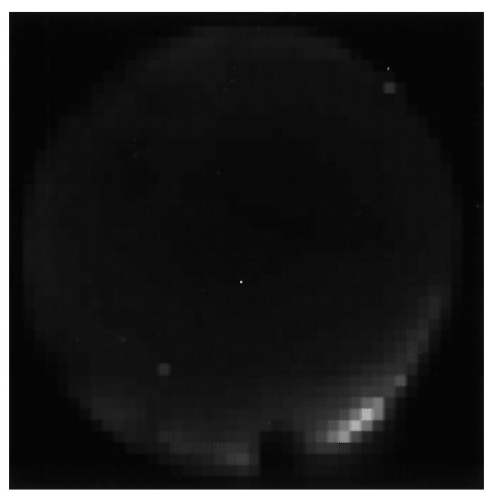

(e) 21:39:59 UT

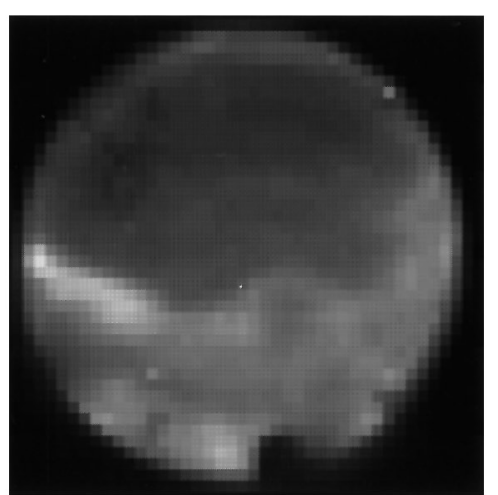

(h) 21:52:08 UT

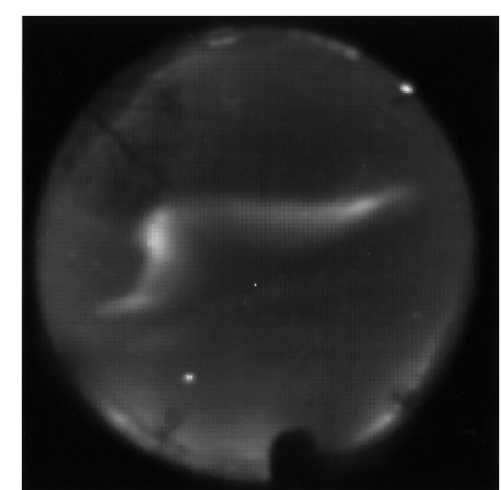

(c) 21:24:52 UT

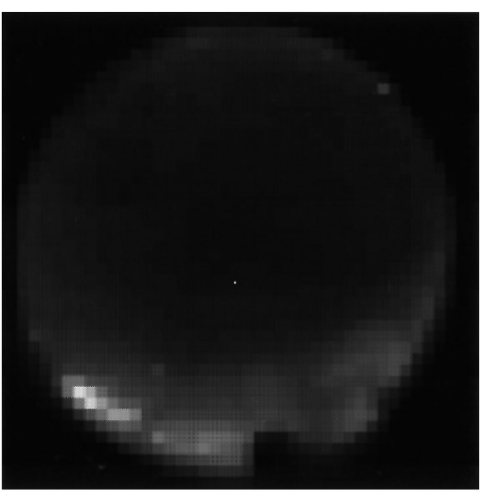

(f) $21: 44: 58 \mathrm{UT}$

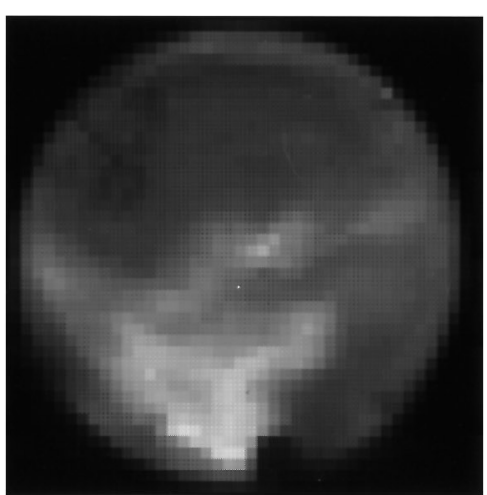

(i) $21: 54: 28$ UT

Fig. 9. A sequence of all-sky camera images showing the motion of arcs in the growth and expansion phases of the substorm. The plates are geographically aligned, with north at the top and east to the

Figure 10a shows the flux of the ionospheric ions in the upflow event measured by EISCAT at $21^{27}$ UT as a function of UT and altitude. The left-hand panel shows ion flux at approximately 10 -s resolution. The arc is clearly visible and delineated by two white lines. The right-hand panel shows the altitude profile of flux integrated over this interval. The flux reaches a maximum value of $4.77 \times$ $10^{14} \mathrm{~m}^{-2} \mathrm{~s}^{-1}$ at about $500 \mathrm{~km}$. The fact that no asymptotic value is reached with increasing altitude may mean that there is an upwelling at F-region altitudes after which some $\mathrm{O}^{+}$sinks back down into the ionosphere again right. The mosaic effect on some of the pictures is due to the dynamic resolution adopted to solve data storage problems

(Lockwood, 1982), but note that the radar is measuring a net upflux above $300 \mathrm{~km}$. We have also calculated the flux of high-energy $\mathrm{O}^{+}$along each of the two major drift echoes measured by MICS for comparison, as illustrated in Fig. 10b, whose first panel shows 2-min (4-spin) averaged count rates for energy channels covering $72.4-101.2 \mathrm{keV}, 113.0-156.7 \mathrm{keV}, 175.4-246.6 \mathrm{keV}$ and 275.4-382.0 keV, and whose second panel gives the corrected $\mathrm{O}^{+}$flux in each of these four energy ranges and for each of the two drift echoes considered. Converting the MICS differential count rates to flux values is acheived 

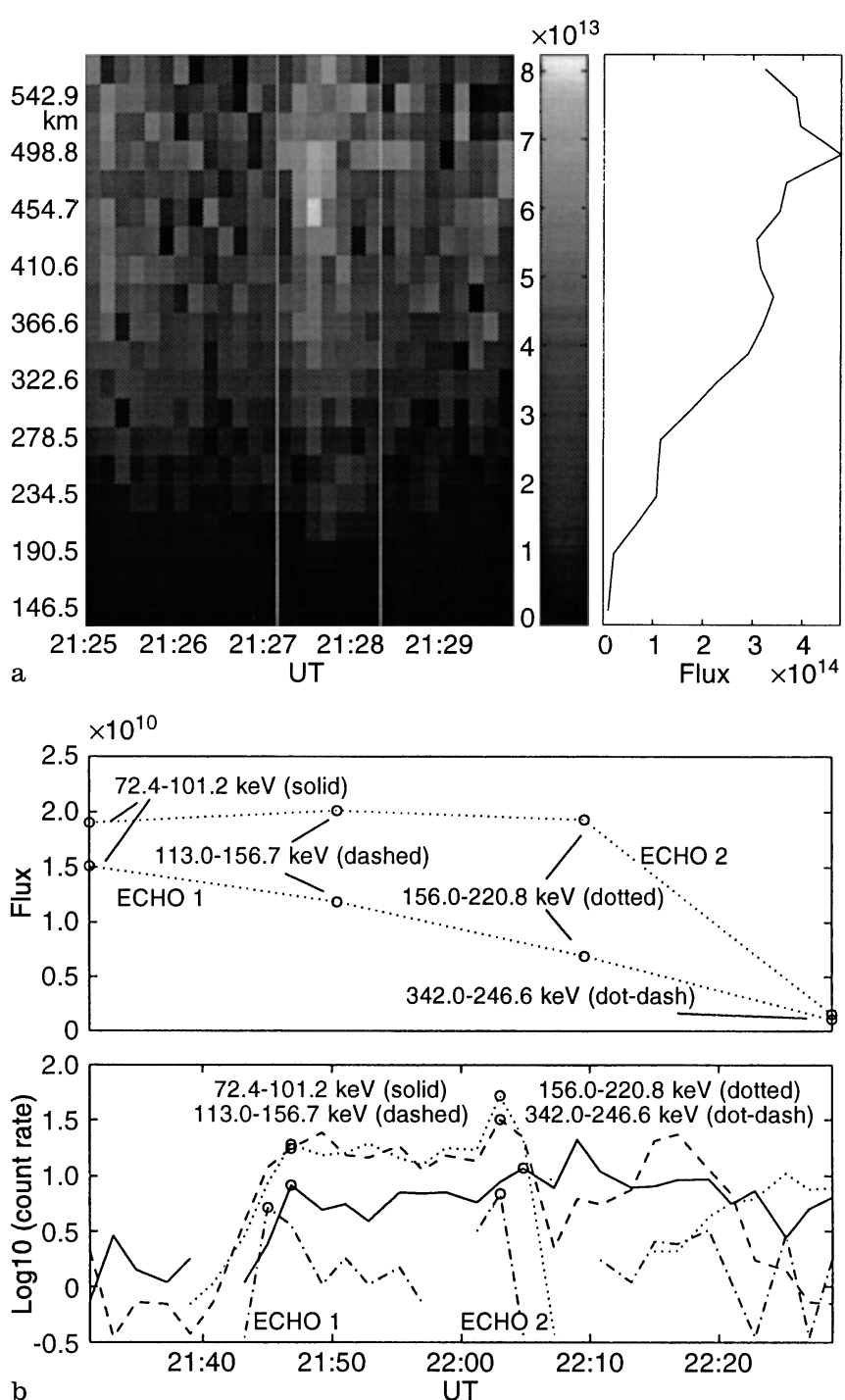

Fig. 10. a The upward flux of ionospheric ions, as measured by EISCAT during transition of the arc through the EISCAT beam at about $21^{27}$ UT. The left-hand panel shows flux $\left(n_{e} \times v_{\|}\right)$as a function of altitude and UT, with the interval containing the arc bounded by two white lines. Immediately to its right is a scale showing flux values. The right-hand panel shows the altitude profile of flux integrated over this time interval (roughly $21^{27}-21^{28}$ ) spanned by the two white lines. b $\mathrm{O}^{+}$-ion flux measured by MICS during the two primary injections (echos 1 and 2) that are visible in Fig. 5. The bottom panel shows the uncorrected count rates (120-s averages) in four energy ranges selected by averaging over a number of the available 32 energy steps. The circles represent the points which lie along the dispersed echo. These are used in the calculation of the actual flux which is shown in the top panel

using the equation:

$j=\frac{d J}{d E}=\frac{C}{G \cdot \Delta E \cdot \eta}$

where $j$ is the differential number flux in $\mathrm{cm}^{-2} \mathrm{~s}^{-1}$ $\mathrm{sr}^{-1} \mathrm{keV}^{-1}, C$ is the measured count rate, $G$ is the instrument's geometric factor, $\Delta E$ is the respective energy band and $\eta$ is the efficiency of the sensor. The correct $j$ for sensor degradation is thus:

$j=j_{\text {meas }}\left(\frac{T C R}{S S D}\right)_{\text {calibration }} \cdot\left(\frac{T C R}{S S D}\right)_{\text {measured }}$

where $T C R$ stands for the total count rate and SSD stands for the count rate at the solid-state detector. The efficiencies and calibration values are available in tabulated form (personal communication, G. Kettmann, CopernicusGesellschaft, Katlenburg-Lindau). The value of the $\mathrm{O}^{+}$ flux $\left(\mathrm{m}^{-2} \mathrm{~s}^{-1}\right)$, summed over all four energy bins, in the first $\left(\mathrm{He}^{2+}\right.$-rich) injection was $3.5 \times 10^{10} \mathrm{~m}^{-2} \mathrm{~s}^{-1}$, and the value of the $\mathrm{O}^{+}$flux in the second $\left(\mathrm{O}^{+}\right.$-rich) injection was $6 \times 10^{10} \mathrm{~m}^{-2} \mathrm{~s}^{-1}$. The strength of the field at CRRES, $B_{C}$, was measured to be $140 \mathrm{nT}$, while the strength of the field in the ionosphere, $B_{I}$, is taken to be constant at $50000 \mathrm{nT}$. The magnetic flux in the flux tube at CRRES, $B_{C} A_{C}$, equals that in the ionosphere end of the tube, namely $B_{I} A_{I}$, where $A$ refers to the local cross-sectional area of the flux tube. Therefore the ratio of the areas, $A_{C} / A_{I}=B_{I} / B_{C}$, and we apply a mapping factor of $50000 / 140 \simeq 360$ to account for the increasing cross-sectional area with altitude of the flux tube between the Earth and CRRES, i.e. we require a flux of $1.25 \times 10^{13} \mathrm{~m}^{-2} \mathrm{~s}^{-1}$ from the ionosphere to explain the injection signature. The upflux measured by EISCAT while the arc was in the radar's beam had a maximum value of about $4.77 \times 10^{14} \mathrm{~m}^{-2} \mathrm{~s}^{-1}$ (Fig. 10a). The ionospheric $\mathrm{O}^{+}$outflux is adequate to explain all the ions seen by CRRES, with the proviso that not all upflowing ions will escape and MICS does not see all ions due to its restricted energy coverage.

For the cleft ion fountain to have been the source of the $\mathrm{O}^{+}$, the flux tube on which they were situated would have had to be transported over the polar cap. The polar cap is situated at approximately $\sim 80^{\circ} \Lambda$ on the dayside, and $\sim 65^{\circ} \Lambda$ on the nightside, such that its diameter at Fregion altitudes is approximately $4000 \mathrm{~km}$. Given a fieldperpendicular plasma velocity of the order of $0.5 \mathrm{~km} \mathrm{~s}^{-1}$, the time required for cleft-ion fountain $\mathrm{O}^{+}$to reach the onset region is well over an hour.

We would expect both injections to have taken place within the substorm current wedge. In the injection modelling, the first, $\mathrm{He}^{2+}$-rich injection is put at $21^{43} \mathrm{UT}$ $\left(22^{34} \mathrm{MLT}\right)$, roughly $30 \mathrm{~min}$ away to the west of EISCAT in MLT and still within the all-sky camera's field of view, since this time difference corresponds to about $430 \mathrm{~km}$ at ionospheric altitudes. At $21^{43} \mathrm{UT}$, the western end of the electrojet was at $352^{\circ} \mathrm{E}$ (geographic) and the injection took a further 2 min to reach CRRES, whose northern magnetic footprint was at geographic longitude $340^{\circ} \mathrm{E}$. It therefore seems likely that this injection originated close to the western end of the substorm electrojet. The second, $\mathrm{O}^{+}$-rich injection is placed at $22^{00} \mathrm{UT}$ and $23^{00}$ MLT, i.e. close to EISCAT's MLT and within the current wedge.

\section{Conclusions}

Due to CRRES' favourable location with respect to EISCAT, we are able to suggest a link between EISCAT 
measurements of oxygen outflow and CRRES measurements of oxygen injections at substorm onset. The injections that have been modelled in this paper form a relatively unusual double injection $-\mathrm{He}^{2+}$ followed by $\mathrm{O}^{+}$ - of the type recently revealed by CRRES data (Grande et al., 1992). It appears that the southward-drifting pre-onset arc visible near Tromsø could well have been a source of $\mathrm{O}^{+}$particles observed by CRRES in the particle injections at onset.

We do not completely rule out the cleft ion fountain as a source of $\mathrm{O}^{+}$, since the growth phase of this substorm lasted for over an hour. The arrival of patches of density in the nightside ionosphere at about the time of onset might mean that cleft-ion-fountain ions ejected upwards at the start of the growth phase reached the onset region in the magnetosphere by the time of onset. However, for $\mathrm{O}^{+}$ions from the cleft ion fountain to have had access to the onset region, there would have had to have been reconnection at the distant neutral line prior to onset. Growth phase reconnection in the tail is not a requirement for the southward-drifting arc source, which was on closed field lines, so these ions would have had direct access to the onset region, which was also on closed field lines (see summary by Kennel, 1992).

Acknowledgements. The authors wish to thank Ron Lepping of the Goddard Space Flight Center for supplying IMP 8 data via the World Data Centre C1 at R.A.L., B. Wilken (PI for MICS) and Boerre for the Tromsø magnetometer data and the director and staff of the EISCAT scientific association. EISCAT is supported by the Science and Engineering Research Council (U.K.), Norges Almenvitenskapelige Forskningsråd (Norway), the Naturvetenskapalige Forskningsråd (Sweden), the Suomen Akatemi (Finland), the MaxPlanck Gesellschaft (Germany), and the Centre National de la Recherche Scientifique (France). R.A.L was in receipt of a USAF grant no. AFOSR850237 for MICS. This research was supported by the U.K. Particle Physics and Astronomy Research Council (PPARC).

Topical Editor D. Alcaydé thanks D. Delcourt and another referee for their help in evaluating this paper.

\section{References}

Baker, D. N., E. W. Hones Jr., D. T. Young, and J. Birn, The possible role of ionospheric oxygen in the initiation and development of plasma sheet instabilities, Geophys. Res. Lett., 9, 1337-1340, 1982.

Bame, S. J., J. R. Ashridge, A. J. Hundhausen, and M. D. Montgomery, Solar-wind ions: ${ }^{58} \mathrm{Fe}^{8+}$ to ${ }^{56} \mathrm{Fe}^{12+},{ }^{28} \mathrm{Si}^{7+}$, ${ }^{28} \mathrm{Si}^{8+},{ }^{28} \mathrm{Si}^{9+},{ }^{16} \mathrm{O}^{6+}$, J. Geophys. Res., 75, 6360-6365, 1970.

Banks, P. M., and T. E. Holzer, High-latitude plasma transport, J. Geophys. Res., 74, 6317-6332, 1969.

Büchner, J. B., and L. M. Zelenyi, Chaotisation of the electron motion as the cause of an internal magnetotail instability and substorm onset, J. Geophys. Res., 92, 13456-13466, 1987.

Chandler, M. O., Observations of polar ion outflows, J. Geophys. Res., 96, 1421-1428, 1991.

Chandler, M. O., Observations of downward-moving $\mathrm{O}^{+}$in the polar topside ionosphere, J. Geophys. Res., 100, 5795-5800, 1995.

Chappell, C. R., Initial observations of thermal plasma composition and energetics from Dynamics Explorer I, Geophys. Res. Lett., 9, 929-932, 1982.

Cladis, J. B., and W. E. Francis, Distribution in magnetotail of $\mathrm{O}^{+}$ ions from cusp/cleft ionosphere: A possible substorm trigger, J. Geophys. Res., 97, 123-130, 1992.
Collin, H. L., R. D. Sharp, E. G. Shelley, and R. G. Johnson, Some general characteristics of upflowing ion beams over the auroral zone and their relation to auroral electrons, J. Geophys. Res., 86, 6820-6826, 1981.

Daglis, I. A., E. T. Sarris, and G. Kremser, Ionospheric contribution to the cross-tail enhancement during the substorm growth phase, J. Atmos. Terr.Phys., 96, 1091-1098, 1991.

Daglis, I. A., S. Livi, E. T. Sarris, and B. Wilken, Energy density of ionospheric and solar-wind-origin ions in the near-earth magnetotail during substorms, J. Geophys. Res., 99, 5691-5703, 1994.

Elphinstone, R. D., J. S. Murphree, and D. J. Hearn, VIKING observations of the UV dayside aurora and their relationship to DMSP particle boundary definitions, Ann. Geophysicae, 10, 815-826, 1991.

Frank, L. A., K. L. Ackerson, and D. N. Yeager, Observations of atomic oxygen $\left(\mathrm{O}^{+}\right)$in the earth's magnetotail, J. Geophys. Res., 82, 129-134, 1977.

Gazey, N. G. J., M. Lockwood, P. N. Smith, S. A. Coles, R. J. Bunting, M. Lester, A. D. Aylward, T. K. Yeoman, and H. Lühr, The development of substorm cross-tail current disruption as seen from the ground, J. Geophys. Res., 100, 9633-9648, 1995.

Ghielmetti, A. G., R. G. Johnson, R. D. Sharp, and E. G. Shelley, The latitudinal, diurnal, and altitudinal distributions of upward-flowing energetic ions of ionospheric origin, Geophys. Res. Lett., 5, 59-62, 1979.

Gorney, D. J., A. Clarke, D. Croley, J. Fennell, J. Luhmann, and P. Mizera, The distribution of ion beams and conics below 8000 km, J. Geophys. Res., 86, 83-89, 1981.

Grande, M., C. H. Perry, D. S. Hall, B. Wilken, S. Livi, F. Søraas, and J. F. Fennell, Composition signatures of substorm injections, in Substorms 1, Proceedings of the 1st International Conference on Substorms, ICS-1, ESA SP-335, 485-490, 1992.

Haerendel, G., S. Buchert, C. La Hoz, B. Raaf, and E. Rieger, On the proper motion of auroral arcs, J. Geophys. Res., 98, 6087-6099, 1993.

Johnson, R. G., Energetic ion composition in the Earth's magnetosphere, Rev. Geophys. Space Phys., 17, 696-705, 1979.

Jones, G. O. L., P. J. S. Williams, K. J. Winser, M. Lockwood, and K. Suvanto, Large plasma velocities along the magnetic field line in the auroral zone, Nature, 336, 231-232, 1988.

Keating, J. G., K. J. Winser, M. Lockwood, F. J. Mulligan, and D. B. Doyle, A statistical study of large field-aligned flows of thermal ions at high latitudes, Planet. Space Sci., 38, 1187-1202, 1990

Kennel, C. F., The Kiruna conjecture, the strong version, in Substorms 1, Proceedings of the 1st International Conference on Substorms, ICS-1, ESASP-335, 99-109, 1992.

Kintner, P. M., M. C. Kelley, A. G. Sharp, A. G. Ghielmetti, C. Temerin, C. Cattell, P. F. Mizera, and J. F. Fennell, Simultaneous observations of energetic $(\mathrm{keV})$ upstreaming and electrostatic hydrogen ion-cyclotron waves, J. Geophys. Res., 84, 7201, 1979.

Klumpar, D. M., Traversely accelerated ions, an ionospheric source of hot magnetospheric ions, J. Geophys. Res., 84, 4229-4237, 1979.

Lockwood, M., Thermal ion flows in the topside auroral ionosphere and the effects of low-latitude, transverse acceleration, Planet. Space Sci., 30, 595-609, 1982.

Lockwood, M., Large-scale fields and flows in the magnetosphereionosphere system, Surv. Geophys., 16, 389-441, 1995.

Lockwood, M., and H. C. Carlson Jr., Production of polar-cap electron density patches by transient magnetopause reconnection, Geophys. Res. Lett., 19, 1731-1734, 1992.

Lockwood, M., J. H. Waite, T. E. Moore, J. F. E. Johnson, and C. R. Chappell, A new source of suprathermal $\mathrm{O}^{+}$near the dayside polar-cap boundary, J. Geophys. Res., 90, 4099-4116, 1985 a.

Lockwood, M., M. O. Chandler, J. L. Horwitz, J. H. Waite, T. E. Moore, and C. R. Chappell, The Cleft Ion Fountain, J. Geophys. Res., 90, 9736-9748, 1985b.

Lopez, R. E., H. E. J. Koskinen, T. Pulkkinen, T. Bösinger, R. W. McEntire, and T. A. Potemra, Simultaneous observation of the poleward expansion of substorm electrojet activity and the tailward expansion of current sheet disruption in the near-earth magnetotail, J. Geophys. Res., 98, 9285-9295, 1993. 
Lyons, L. R., and D. J. Williams, Quantitative aspects of magnetospheric physics, D. Reidel, Dordrecht, 1984.

Moore, T. E., J. H. Waite, M. Lockwood, M. O. Chandler, C. R. Chappell, M. Sigiura, D. R. Weimer, and W. K. Peterson, Upwelling $\mathrm{O}^{+}$ions, a case study. Poster paper, Fall AGU meeting (see EOS Transactions of the AGU, 65, 1056), 1984.

Murphree, J. S., R. D. Elphinstone, M. G. Henderson, L. L. Cogger, and D. J. Hearn, Interpretation of optical substorm onset observations, J. Atmos. Terr. Phys., 55, 1159-1170, 1993.

Orr, D., and M. Craymonson, The location of substorms using mid-latitude magnetometer arrays, in Substorms 2, Proceedings of the 2nd International Conference on Substorms, ICS-2, 435-438, 1994.

Prange, R., Energetic $(\mathrm{keV})$ ions of ionospheric origin in the magnetosphere, a review, Ann. Geophysicae, 34, 187-213, 1978.

Samson, J. C., L. R. Lyons, P. T. Newell, F. Creutzberg, and B. Xu, Proton aurora and substorm intensifications, Geophys. Res. Lett., 19, 2167-2170, 1992a.

Samson, J. C., D. D. Wallis, T. J. Hughes, F. Creutzberg, J. M. Ruohoniemi, and R. A. Greenwald, Substorm intensifications and field-line resonances in the nightside magnetosphere, J. Geophys. Res., 97, 8495-8518, 1992b.

Shelley, E. G., W. K. Peterson, A. G. Ghielmetti, and J. Geiss, The polar ionosphere as a source of energetic magnetospheric plasma, Geophys. Res. Lett., 9, 941-945, 1982.
Wahlund, J.-E., H. Opgenoorth, I. Häggström, K. J. Winser, and G. O. L. Jones, EISCAT observations of topside ionospheric outflows during auroral activity, revisited, J. Geophys. Res., 97, 3019-3035, 1992

Waite, J. H., T. Nagai, J. F. E. Johnson, C. R. Chappell, J. L. Burch, T. L. Killeen, P. B. Hays, G. R. Carignan, W. K. Peterson, and E. G. Shelley, Escape of suprathermal $\mathrm{O}^{+}$ions in the polar cap, $J$. Geophys. Res., 90, 1619-1630, 1985.

Wilken, B., W. Weiss, G. Kremser, H. Sommer, S. Livi, D. Hall, M. Grande, K. Slater, J. F. Fennell, R. Koga, D. Chenette, and N. Katz, The Magnetospheric Ion Composition Spectrometer MICS onboard the Combined Release and Radiation Effects Satellite (CRRES), J. Spacecr. Rockets, 29, 585-591, 1992.

Winser, K. J., G. O. L. Jones, P. J. S. Williams, and M. Lockwood, Observations of large field-aligned flows of thermal plasma in the auroral ionosphere, Adv. Space Res., 9, 57-63, 1989.

Yau, A. W., B. A. Whalen, W. K. Peterson, and E. G. Shelley, Distribution of upflowing ionospheric ions in the high-latitude polar cap and auroral ionosphere, J. Geophys. Res., 89, 55075522,1984

Yeoman, T. Y., D. K. Milling, and D. Orr, Pi2 pulsation polarization patterns on the U.K. Sub-Auroral Magnetometer Network (SAMNET), Planet. Space Sci., 38, 589, 1990.

This article was processed by the author using the LATEX style file cljour 2 from Springer-Verlag. 